\title{
Study and Modelling of Factors Driving the Performance of Solar Modules
}

\author{
Janvier Kamanzi ${ }^{1}$ and Matthew Sibanda ${ }^{2}$ \\ ${ }^{1}$ Cape Peninsula University of Technology, Centre of Distributed Power \\ and Electronic Systems (CDPES), Symphony Way, P. O. BOX 1906, \\ Bellville 7535, South Africa \\ ${ }^{2}$ Mangosuthu University of Technology, Department of Electrical Engineering, \\ P. O. BOX 12363, Jacobs, Durban 4026, South Africa \\ E-mail: kajanois@gmail.com; sibanda.matthew@mut.ac.za
}

Received 15 August 2017; Accepted 28 October 2017;

Publication 24 November 2017

\begin{abstract}
Optimal exploitation of the costless and self-sustaining solar energy has been a concern of much research in response to pressuring energy demands in one hand and the effects of relying on energy sources which are harmful to the humans and the environment on the other hand. The conversion efficiencies of photovoltaics (PVs) as well as their production costs have therefore been research targets. However, factors such as unsatisfactory exposure to the available sunlight, weather-dependence of the sunlight and shading, temperature rise at cells' junctions as well as manufacture related-defects still remain major causes of PVs' underperformance which manifests in lower levels of output power and efficiency. The dynamics of the output power or current with respect to the potential differences at cells' junctions are usually graphically illustrated with two-axis plots, which imply that only two parameters get evaluated against each other at a time.

In this paper, three-axis plots were further used to evaluate the output parameters with respect to a simultaneous change of any other two parameters involved in the model of the PV cells; which gives a more realistic and comprehensive picture of the performance of PV cells. In addition, causes affecting the output and efficiency levels of cells are critically reviewed
\end{abstract}

Journal of Green Engineering, Vol. 7-3, 333-360.

doi: 10.13052/jge1904-4720.731

This is an Open Access publication. (c) 2017 the Author(s). All rights reserved. 
along with strategies adopted to address them. A handful of recommendations concerning optimizing the usage of sunlight at disposal are within provided as well.

\section{Introduction}

Notable research has targeted the optimal use of the massive and readily available solar energy to keep up with global energy demands, as well as the consequences of using fossil fuels as the main source of energy production. PV cells, as energy-conversion agents, suffer from setbacks in their performance, due to factors of external and internal sources which affect their outputs and efficiencies.

The history in solar energy usage dates as far as in the era before Christ (BC), precisely in the 7th century according to $\tilde{A}$ et al. (2011) in a chronologically narrated timeline. It all started with the Greeks and Romans making use of the concentrated sun's rays to light candles during religious practices. The Greeks exploited this Archimedes' discovery as a war weapon they used to set alight the wooden ships of the adversaries. Solar concentrating technology using magnifying lenses was later viewed as one of the sources of heat to run engines. The timeline of solar energy from the same authors is summarized in the next paragraphs of this heading.

The PV effect was only discovered in 1839 by a French scientist Edmond Becquerel when he was conducting experiments on the conductivity of an electrolyte. He realized that conductivity across the electrodes would increase when the electrolyte was being exposed to more sunlight. However, photo electricity effect was revealed in 1916, just two years after the discovery of the existence of the potential barrier in Silicon (Si) by Jan Czochralski, a Polish scientist. The findings on PV effects led to the invention of Si-PV cells in 1954 which triggered the launch of many solar-powered earth-orbiting satellites in the following five years as well as terrestrial solar-powered projects around the world. At that epoch, there was a surge of a multitude of companies manufacturing PVs for commercial purposes.

With the efficiency and production costs being the driving factors, the need of a more realistic approach of producing PVs was imminently being jointly sought for by manufacturers and governments. One of the approaches was to classify PVs in categories also known as generations depending on the application and efficiency levels required. Three generations were then identified. 
Kibria et al. (2014) and Bagnall \& Boreland (2008) have discussed the classification of PVs according to generations: first generation $(1 \mathrm{G})$, second generation $(2 \mathrm{G})$ and third generation $(3 \mathrm{G})$. These generations have been outlined based on the correlation between production-cost, efficiency and applications of PV cells' efficiency.

$1 \mathrm{G}$ represents the oldest generation of PVs which is based on single crystal $\mathrm{Si}$ cells (c-Si) and multi-crystal $\mathrm{Si}$ (mc-Si) produced on wafers. For 2-3 W power each wafer, many cells are put together to form a panel according to the power required to be realized. In terms of crystals, single or mono crystal cells are the ones made with only one crystal grain, whereas multi crystal cells consist of a multitude of crystal grains each. Though mono crystal offer higher efficiencies than mc-Si cells, the latter dominate the word market at a rate of $63 \%$ due to their low production cost (Bagnall \& Boreland, 2008). 1 G PV lab efficiencies could hit a high of $24.7 \%$ whereas best module efficiencies were estimated at $21.7 \%$ (Kibria et al., 2014). However, in their previous work, Bagnall \& Boreland (2008) had indicated that 1 G PV efficiencies would be of order $18-21 \%$ in general. They also stipulated that the efficiencies of mc-Si cells would range between 13-14\%. However, the same authors still highlighted concerns about costs involved in $1 \mathrm{G} \mathrm{PV}$ production. They indicated that half of that cost was spent on mechanical work involved in developing thick Si wafer $(200-500 \mu \mathrm{m})$. The authors suggested that the reduction of the thickness of a Si-wafers could lead to the reduction of the production cost.

Second generation (2 G) PVs were conceived and designed in a way that would help reduce the costs involved in the development of $1 \mathrm{G}$ PVs while keeping the conversion efficiencies to the closest. The approach would consist of chopping off the cost of the material deemed unimportant from the production equation of $2 \mathrm{G} \mathrm{PVs}$. The production technology explored a variety of materials including amorphous $\mathrm{Si}$ cells (a-Si) thin-film, mc-Si, Cadmium-Telluride (CdTe) and Copper-Indium-(Gallium)-Selenide $\left(\mathrm{CuIn}(\mathrm{Ga}) \mathrm{Se}_{2}\right)$ solar cells. Their efficiencies are a bit lower than those of $1 \mathrm{G} \mathrm{PV}$ cells and so is their production cost, since the active material is deposited on low-cost substrates, a glass for instance. With a thin thickness $(1-10 \mu \mathrm{m})$, the active material of $2 \mathrm{G}$ PVs could capture much light and achieve a conversion efficiency of $10 \%$. Lab tests revealed $16.5 \%$ and $18.4 \%$ efficiencies for CdTe and Copper-Indium-(Gallium)-Selenide $\left(\mathrm{CuIn}(\mathrm{Ga}) \mathrm{Se}_{2}\right.$ (CIGS) respectively, and module lowest efficiencies of order 10.7\% (Green, 2011). According to Segal et al. (2004), 2 G PVs have been appreciated for their aesthetic appearance and flexible application on 
various kinds of surfaces. Thin films also offer an advantage of being deposited on flexible substrates, thus enlarging the field of applications unlike wafer cells. They can be applied to walls, car windows and so forth. Furthermore, $2 \mathrm{G}$ PVs can be reproduced in larger area (up to $6 \mathrm{~m}^{2}$ ) while wafer cells can only be available in wafer dimensions (Bagnall \& Boreland, 2008).

The design of third-generation ( $3 \mathrm{G}$ ) PVs aims at achieving ultrahigh efficiencies almost incurring same costs as used to produce $1 \mathrm{G}$ and $2 \mathrm{G}$ PVs. The production of $3 \mathrm{G} \mathrm{PVs}$ focus on making use of proven and viable technologies such as nanocrystal-based cells, polymer-based cells, dye-sensitized cells and concentrated PV cells (CPV) (Kibria et al., 2014). Though $3 \mathrm{G}$ PVs are not commercially available yet, hopes are high when one looks back at 32\% efficient GaInP/GaAs/Ge triple-junction PV cells which are dedicated to space applications due to too high costs involved in their development (Bagnall \& Boreland, 2008).

Further efforts towards making use of cleaner energy sources developed into combining PVs with other renewable energy sources in systems referred to as cogeneration. From a review conducted by Parida et al. (2011), PVs have been involved in a variety of cogeneration or hybrid systems with great success. Hybrid power generation refers to a combination of PVs with conventional forms of power generation (such as coal, gas, and hydro) or a renewable energy source (like wind, fuel cells, to name just a few). Having remote area in mind, studies conducted, showed that a stand-alone PV-wind power cogeneration systems was more effective than PV and wind operating in independent standalone modes. In the same stream, PV-Fuel cell hybrid system running on an electrolyser could be used to generate the hydrogen while a fuzzy regression could help track the maximum power point.

However, the crucial problem of producing high efficiency PV cells on low-production costs still remains and is worsened by other external factors affecting cells' conversion ratios.

\section{External Factors Affecting the Performance of PVs}

In terms of external factors that further affect PV cells efficiencies, the following are viewed as the main factors: 1) Poor irradiance capturing ratio (Yilmaz et al., 2015), 2) Manufacture or factory related defects and ageing (Bhushan, 1999; Jordan \& Kurtz, 2013), 3) heat effect (Sabri, Benzirar, \& Student, 2007) and 4) unfriendly weather and shading (Pachpande \& Jalgaon, 2012). 


\subsection{Poor Irradiance Capturing Ratio}

PV modules, typically fixed-tilt ones which are laid flat on buildings' rooftops, are characterised by the inability of making use of the available sunlight. They cannot actually synchronise with the sun's apparent movement on the course of the day and cannot therefore take advantage of the available light for maximum electrical energy conversion.

As such, PVs will only be exposed to sunlight at maximum at noon over a whole day (Figure 1) with sunset and sunrise times assumed to be 6:00 and 18:00 respectively. Moreover, with the sun shuttling between the two tropics yearly, it exposes the shortcoming of fitting PV modules at fixed tilt angle on the other hand (You, Hao, \& Adele, n.d.).

\subsection{Heat Effects on PV Efficiency}

Only a little amount of the solar energy contained in the light spectrum is converted into electricity while a huge portion embedded in the heat spectrum negatively impacts on energy conversion efficiencies performance of PV cells and contributes to the early degradation and ageing. Chow (2010) indicated

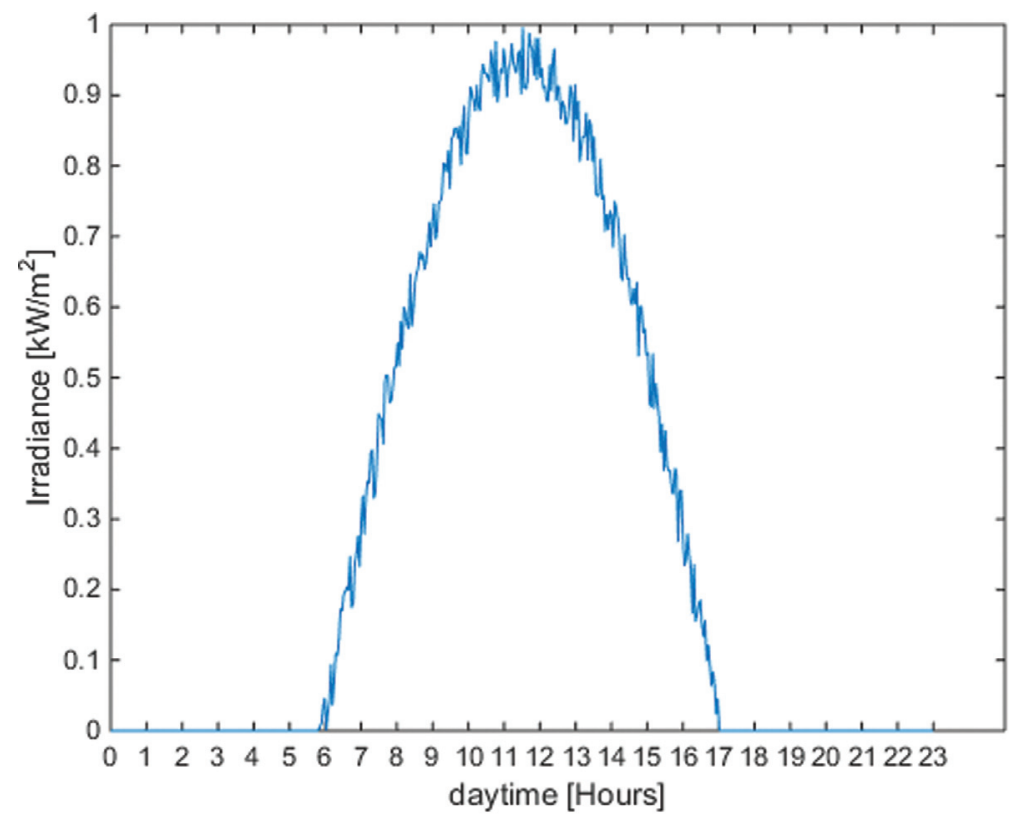

Figure 1 Daily irradiance ideal distribution of a PV panel. 
that common PV cells could only exploit the light which is estimated to $17 \%$ of the incident solar energy. After deduction of the energy reflected to the environment, an amount above $50 \%$ of the incoming energy is absorbed by the cells in the form of heat. If not dissipated, the heat or thermal energy lowers PV cells' efficiency and causes permanent damages of the semiconducting junctions. The same author also mentioned that a fall of $0.4 \%$ in efficiency would be observed for each Celsius degree increase. However, other authors converged on a bit higher figure of $0.5 \%$ decrease (Jordan \& Kurtz, 2013; Moharram, Abd-Elhady, Kandil, \& El-Sherif, 2013). Also, studies conducted showed that the open-circuit voltage (Voc) changes much faster than the shortcircuit current (Isc) at respective rates of $0.37 \%$ and $0.05 \%$; which inflicts a decrease of $0.5 \%$ in the maximum power point (MPP) per each temperature unit increase. The impact of temperature fluctuations on the characteristics of solar modules i.e. current or power versus the voltage are assessed and obtained based on mathematical and electrical models, solar simulators or experimental measurements.

\subsection{Solar Cell Models}

Solar cells are the core components of solar modules; they form PV arrays when they are interconnected. Therefore, the knowledge of the performance of a cell will surely inform on the solar modules'. In the study and analysis of the dynamics of PV cells parameters which depend on factors such as temperature and illumination, the cells physical models have been established. Electrical diagrams have been then used as equivalent models of PV cells and according mathematical representations derived. Electrical models for PV cells usually comprise a diode and/or shunt and series resistances. Multi-diode electrical models have also been explored for the sake of the accuracy on the performance of PV cells. In this paper, a basic model which consists of a single diode was considered. For practical concerns, empirical models for PV modules have been developed in order to accommodate the parameters of solar modules which are normally provided in datasheets.

\subsubsection{Solar cells mathematical model}

The mathematical models established at first are in the form of electrical circuit. The input variables, constants and coefficients reflect an electrical network. There are three main types of models referred to when it comes to studying and analysing PV cell performance. 


\section{a) Ideal model}

The ideal model of PV cells assumes that there are no internal losses. Its electrical representation consists of a current source which is in parallel with a diode. Such an electrical model is mathematically described by Equation (3).

Equation (3) is obtained by first applying Kirchhoff's law on the diagram in Figure 2 and making the output current the subject of the equation. The output current is then equal to the direct difference between the input and diode currents (Equation (1))

$$
I=I_{p h}-I_{d}
$$

Where $I_{p h}$ is the photocurrent [A], $I_{d}$ is current flowing through the diode [A] and $R_{L}$ is the load resistance.

With the current flowing through the diode being given by Equation (2), the output current is given by Equation (3).

$$
\begin{aligned}
I_{d} & =I_{o}\left[\exp \left(\frac{V}{N V_{T}}\right)-1\right] \\
V_{T} & =k T_{c} / q \\
I & =I_{p h}-I_{o}\left[\exp \left(\frac{V}{N V_{T}}\right)-1\right]
\end{aligned}
$$

$I_{s}$ is the diode saturation current [A], $N$ is the ideality factor, $V$ is the cell output voltage [V], $V_{T}$ is the thermal voltage [V], $k$ is the Boltzmann constant equal to $1.38 \times 10^{-23}[\mathrm{~J} / \mathrm{K}], q=1.6 \times 10^{-19} \mathrm{C}$ is the electronic charge [C] and $T_{c}$ is the absolute temperature of the cell $[\mathrm{K}]$.

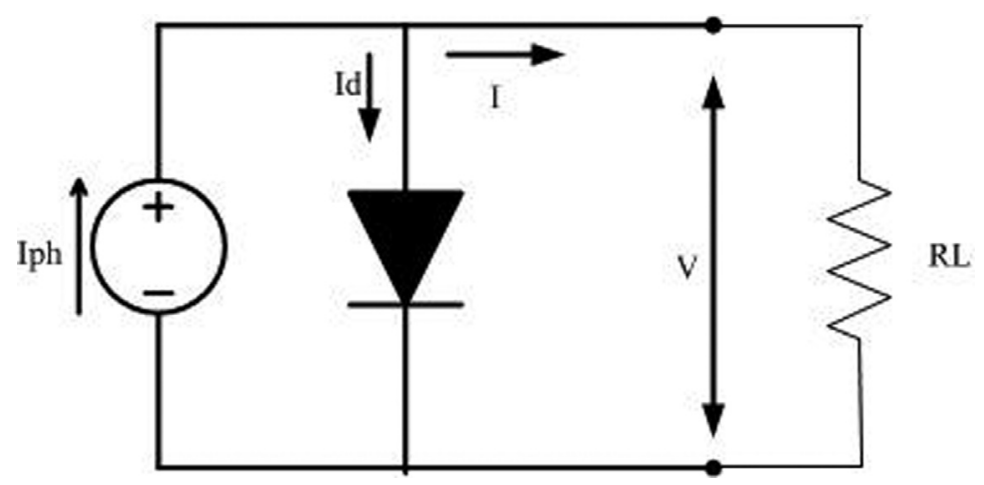

Figure 2 Electrical representation of a PV cell deal model. 


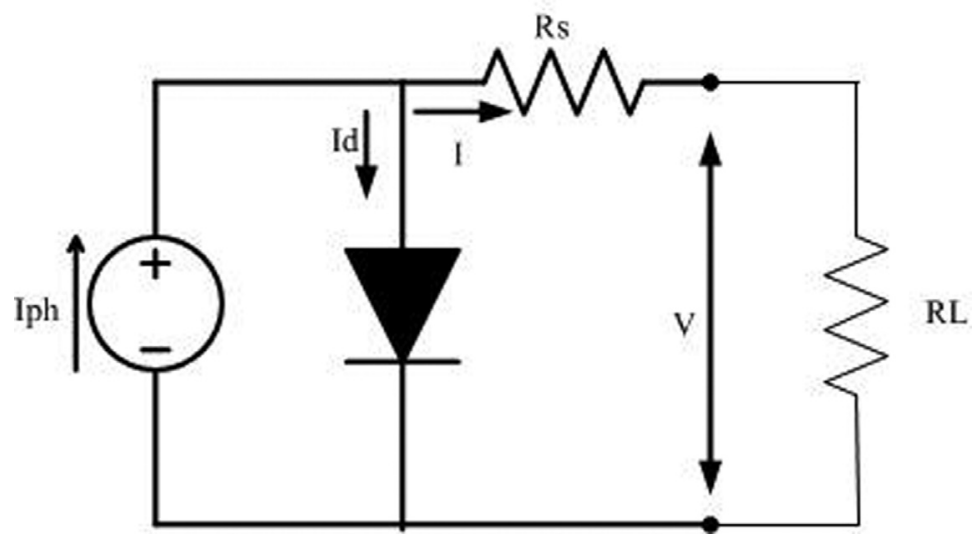

Figure 3 PV cell electrical model with a series resistance.

\section{b) Non-ideal model}

A non-ideal model of PV cells takes into account losses which occur within a cell. Its electrical model is illustrated with the help of a current source (photocurrent) placed in parallel with a diode and then in series with a resistance (Figure 3).

The approach used to derive the mathematical model for the non-ideal model of a PV cell is similar to the one used for the previous model. The flow of the output current through a series resistance $R_{s}[\Omega]$ increases the output voltage of a voltage equal to $I R_{S}[\mathrm{~V}]$; which yields a mathematical model in Equation (5).

$$
I=I_{p h}-I_{o}\left[\exp \left(\frac{V+I R_{s}}{N V_{T}}\right)-1\right]
$$

\section{c) Non-ideal model with both series and shunt resistance}

The rational of this model is that PV cells should normally be represented by models which are more accurate. However, the model above (Equation (5)) does not account for electrical losses which are due to manufacture-related defects. To address for this shortfall, a shunt resistance was inserted just between the diode and the series resistance in the circuit diagram (Figure 4). As such, the amount of current flowing through that shunt resistance $R_{s h}[\Omega]$ will be deducted from the output current. The shunt current $I_{s h}[\mathrm{~A}]$ is obtained by applying Ohm's law to the output loop of the circuit (Equation (6)); the practical model is then derived in Equation (7). 


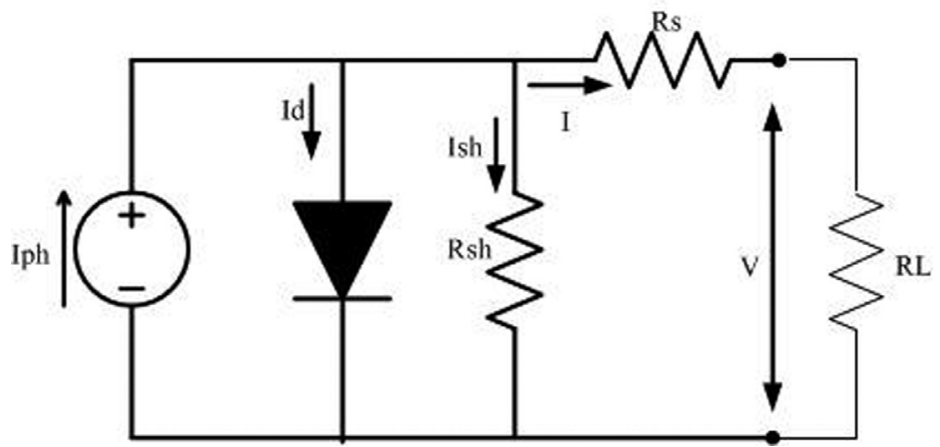

Figure 4 PV cell electrical model with shunt and series resistances.

$$
\begin{aligned}
I_{s h} & =\frac{V+I R_{s}}{R_{s h}} \\
I & =I_{p h}-I_{o}\left[\exp \left(\frac{V+I R_{s}}{N V_{T}}\right)-1\right]-\left[\frac{V+I R_{s}}{R_{s h}}\right]
\end{aligned}
$$

The last model having two resistances included within is more practical. The first one has only a series resistance while the second has a shunt resistance in addition. The shunt resistance, which is assumed to be very large, represents the surface quality along the periphery of the cell whereas the series resistor, very small results from the ohmic contact and the semiconductor internal resistance of the cell. A cell with a low shunt resistance will therefore be prone to huge losses in output current and power.

\subsubsection{Solar module empirical model}

A solar module is made of a set of PV cells which are inter-connected. Depending on the power required for specific values of current and voltage, series-connected cells are put in parallel. The design of solar modules usually advises an arrangment of cells which provides the power required using low current levels. This is due to demands of large-size cables and largely rated protection devices which are associated with high operating currents. The model for solar modules for this study considers arranging PV cell models in series, which results in a constant current and multiplied cell output voltage. A shunt and a series resistances are also included in the model in order to ensure that possible types of power losses are catered for.

Furthermore, as solar modules'parameters are specified and rated in the manufacturer's datasheet, it has been found more convenient to develop their models based on the same specifications. In addition, environment-related 
parameters involved in the actual operation such as irradiance and temperature have been considered in development of the model for solar modules. Since the parameters of solar cells are dynamic relatively to nominal values of irradiance and temperature, the values of parameters provided in the manufacturers datasheet serve as reference to the parameters observed during the operation. The photocurrent is given by Equation (8), the saturation current for the cell junction by Equation (9) and the thermal voltage by Equation (10).

In Equation (9), the actual photocurrent $I_{p h}[\mathrm{~A}]$ is expressed in terms of the actual and nominal values of the irradiance and the temparature.

$$
I_{p h}=\frac{G}{G_{n}}\left[I_{p h n}+k i\left(T_{c}-T_{n}\right)\right]
$$

Where $G$ and $G_{n}$ are actual and nominal irradiance [W/m $\left.{ }^{2}\right]$ respectively, $I_{p h n}$ is the nominal photocurrent [A], $k i$ is the temperature constant current $[\mathrm{A} / \mathrm{K}]$, $T_{c}$ and $T_{n}$ are cell's actual and nominal temperatures $[\mathrm{K}]$ respectively.

As the temperature changes, the saturation current $I_{o}[\mathrm{~A}]$ changes according to Equation (9).

$$
I_{o}=I_{o n}\left(\frac{T_{c}}{T_{n}}\right)^{3} \exp \left[\frac{E_{g}}{V_{T n}}\left(\frac{1}{T_{n}}-\frac{1}{T_{c}}\right)\right]
$$

Where $I_{o n}$ is the nominal saturation current $[\mathrm{A}], E_{g}$ is the cell junction voltage [V].

The nominal saturation current itself is derived with respect to the nominal short circuit current $I_{\text {scn }}$ [A], the nominal open-circuit voltage of the module $V_{o c n}[\mathrm{~V}]$ and the nominal thermal voltage $V_{T n}[\mathrm{~V}]$ and the cell's junction ideality factor $N$ (Equation (10)).

$$
I_{o n}=\frac{I_{s c n}}{\exp \left(\frac{V_{o c n}}{N V_{T n}}\right)-1}
$$

Thermal voltage $V_{T n}[\mathrm{~V}]$ is quantified by using Equation (11). It is important to notice the involvement of the number of series-connected cells $N_{s}$. It is at this point that the model of a solar module is actually being relaized.

$$
V_{T n}=N_{s} k \frac{T_{n}}{q}
$$

The model of a solar module in actual conditions of operation is then establisehd by substituting the parameters in Equations (8)-(10) either Equations (4), (5) or (7) depending on the model under which the module is being studied. 


\subsection{Thermal Effects in Graphs (PV Cells' Performance vs. Thermal Fluctuations)}

The performance of PV cells is basically estimated based on electrical equivalent circuit. This section portrays the effects of temperature on the output of a fictive PV module given some parameters. A complete model consisting of a diode in parallel with a shunt resistor and a series resistor (Figure 4) was used to evaluate the characteristics of a fictive PV array of which the datasheet information are gathered in Table 1.

The performance of the module was studied for both positive and negative temperature gradients in two dimensions (2D) and three dimensions (3D).

In 2D, only two parameters get evaluated against each other while a third parameter is kept constant. For instance, the plot of the change in the current of the module versus the change in the voltage has to be made when the temperature is set at a certain constant value. The same applies for the power versus voltage. The voltage-current (V-I) and the voltage-power (P-V) curves are shown in Figures 5 and 6.

To evaluate the performance of the module in $2 \mathrm{D}$ over a range of temperatures, one has normally to repeat the process for each discrete value of temperature in order to sketch V-I and P-V curves. A MATLAB code was developed to accept a row matrix of temperatures, do required computations and plot the current and power characteristics for each temperature value. Figures 7 and 8 illustrate the change in the V-I and V-P characteristics if the module was operated in extreme temperatures of the space environment (between the sunlight and the orbit eclipse). With reference to the nominal operation temperature, graphs show that a gain of about $8 \mathrm{~V}$ can be

Table 1 Specifications of the solar module under study

\begin{tabular}{ll}
\hline Parameter & Value \\
\hline Open- circuit voltage $V_{O C}[\mathrm{~V}]$ & 32.9 \\
Number of series-connected cells & 54 \\
Short-circuit current $I_{S C}[\mathrm{~A}]$ & 8.21 \\
Ideality factor $N$ & 1.2 \\
Temperature-current constant $k i[\mathrm{~A} / \mathrm{K}]$ & 0.0032 \\
Temperature-voltage constant $k v[\mathrm{~V} / \mathrm{K}]$ & -0.123 \\
PV cell band gap $E g[\mathrm{~V}]$ & 1.12 \\
Series resistance $R_{s}[\Omega]$ & 0.221 \\
Shunt resistance $R_{s h}[\Omega]$ & 415.405 \\
Nominal irradiance $G_{n}\left[\mathrm{~W} / \mathrm{m}^{2}\right]$ & 1000 \\
Nominal temperature of operation $T_{n}\left[{ }^{\circ} \mathrm{C}\right]$ & 25 \\
\hline
\end{tabular}




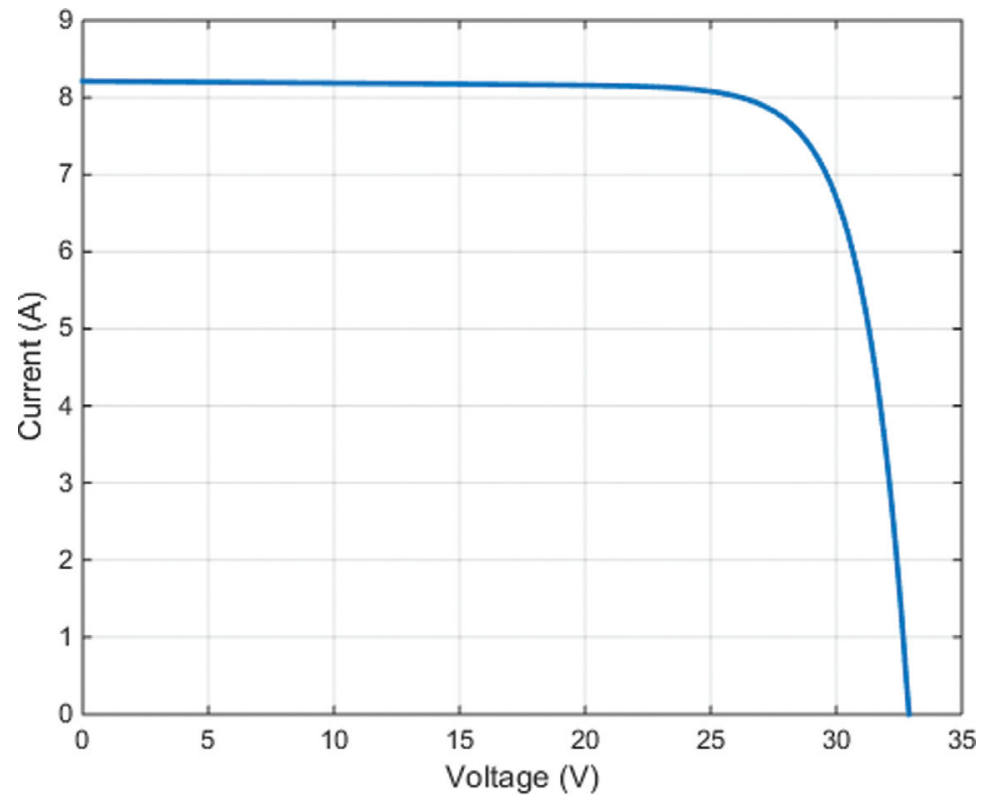

Figure 5 Current-Voltage characteristic at operating the nominal temperature.

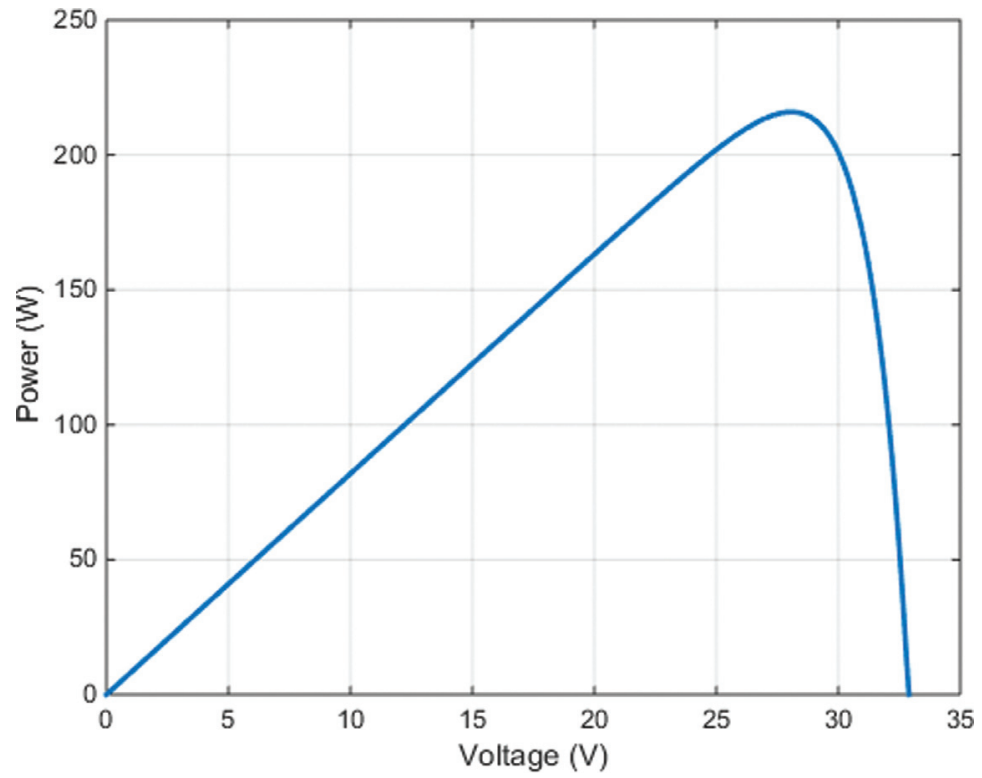

Figure 6 Power-voltage characteristic at the nominal operating temperature. 


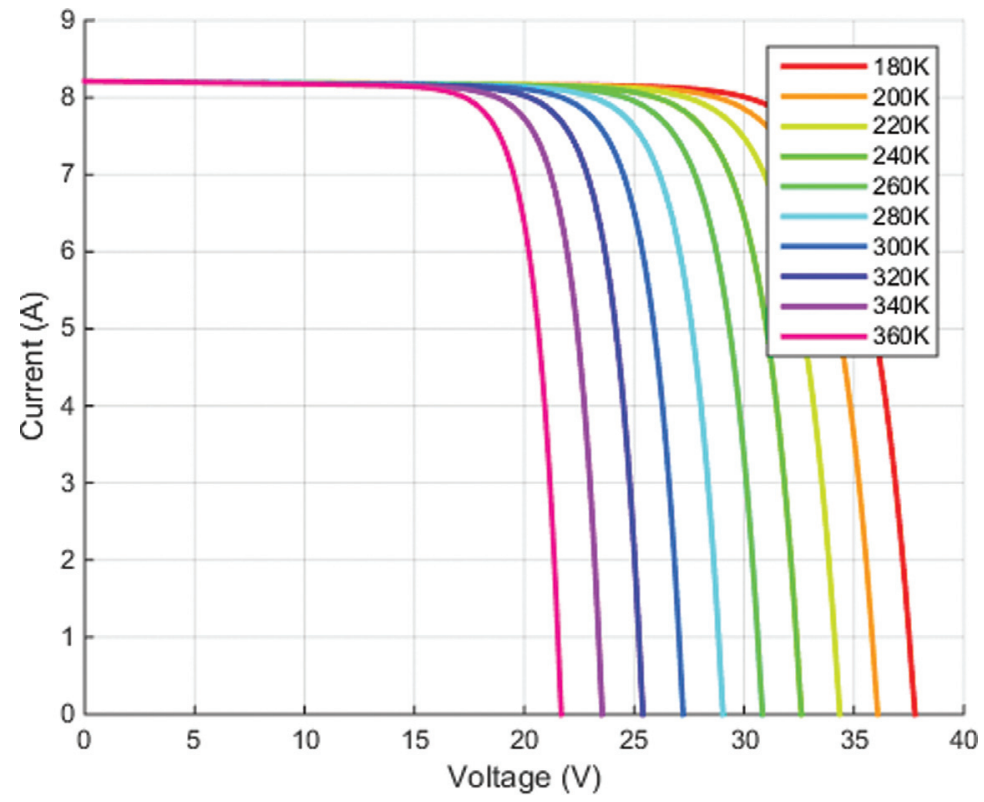

Figure 7 Thermal effects on the open-circuit voltage between $180 \mathrm{~K}$ and $360 \mathrm{~K}$.

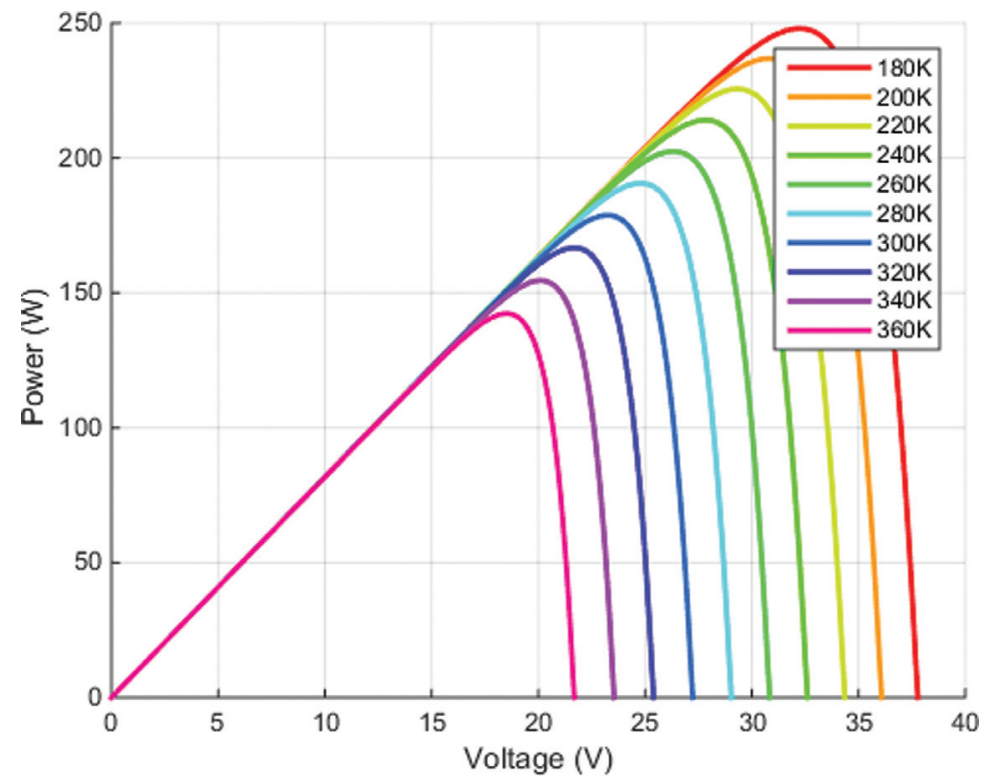

Figure 8 Thermal effect on the power for temperature between $180 \mathrm{~K}$ and $360 \mathrm{~K}$. 
realized when the module is operated at $180 \mathrm{~K}$ whereas a loss of more than 10 $\mathrm{V}$ may be incurred when the module's temperature rises to $360 \mathrm{~K}$. Similarly, a gain of $30 \mathrm{~W}$ and a loss of up to $70 \mathrm{~W}$ are expected for the mentioned extreme temperatures relatively to the nominal temperature of operation.

The performance curves of PV modules have mostly been graphically represented in $2 \mathrm{D}$, only relating two parameters on a curve at a time. In this study, the researcher has introduced the possibility of relating three parameters of the PV module in one graph. Parameters taken into consideration are the voltage, the current, the power and the temperature. Thus, V-I-T graphs (relating the voltage change with respect to the current and temperature) P-I-V graph (evaluating the power against the current and voltage), and P-I-T (reflecting the power change with regards to the temperature and current) are displayed in Figures 9, 10 and 11. 3D graphs which are plotted considering a temperature range of $180 \mathrm{~K}$ to $500 \mathrm{~K}$ show how the voltage and the power linearly decreases along the line of maximum current as the temperature increases.

It is noteworthy to mention the advantages of characterizing the parameters of solar cells or modules in 3D as compared to a profile representation (2D) of the same parameters. Firstly, 3D plots provide a more realistic and overall picture of how parameters influence each other. While evaluating

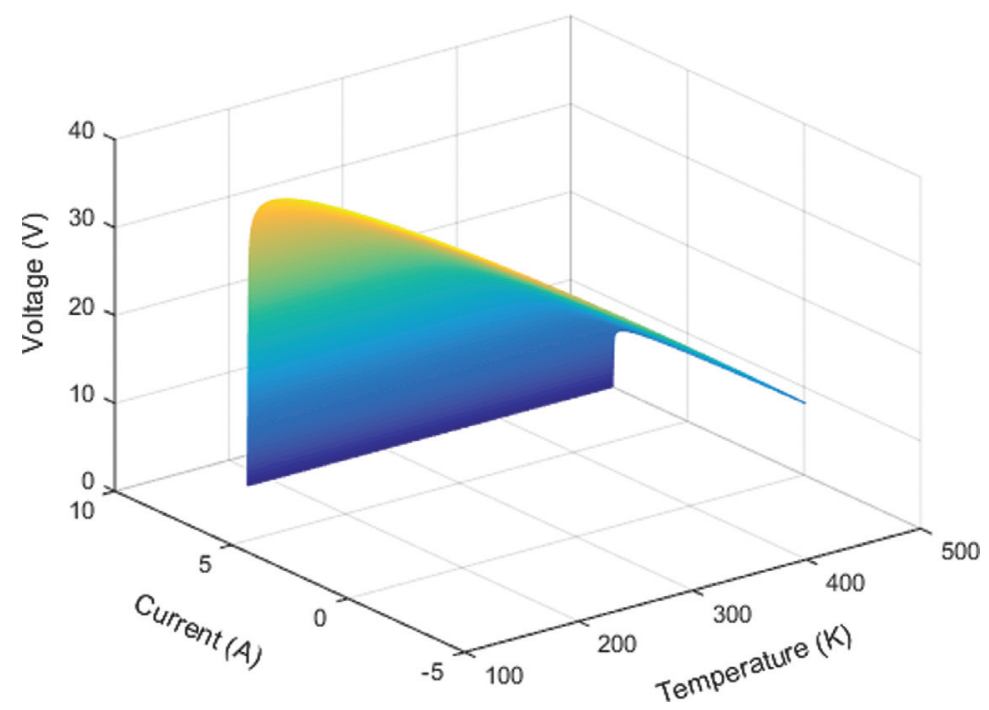

Figure $93 \mathrm{D}$ plot of Voc versus current and temperature when PV cooled between $500 \mathrm{~K}$ and $180 \mathrm{~K}$. 


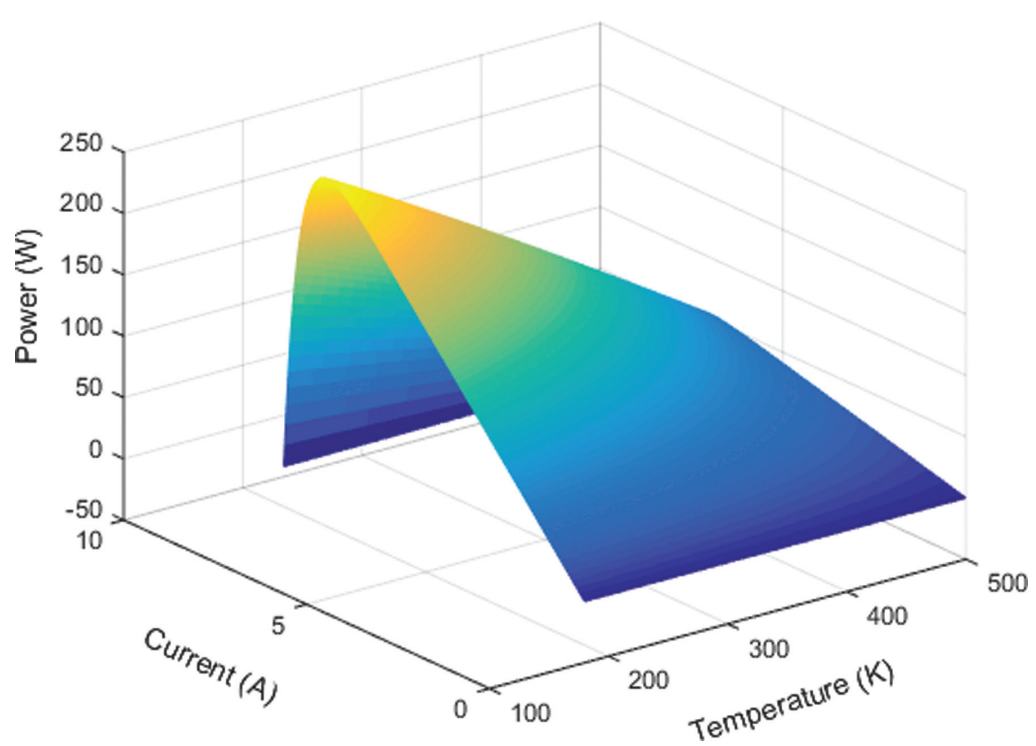

Figure $103 \mathrm{D}$ plot of the power versus the current and temperature when PV cooled from $500 \mathrm{~K}$ to $180 \mathrm{~K}$.

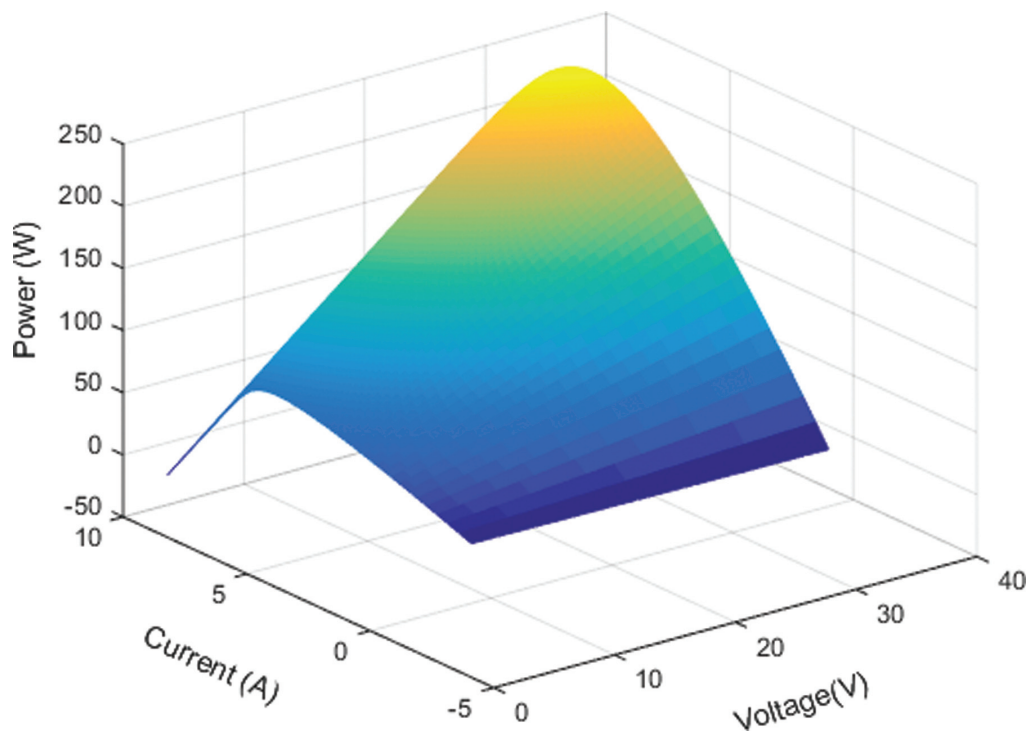

Figure $113 \mathrm{D}$ plot for power versus current and voltage when PV cooled from $500 \mathrm{~K}$ to $180 \mathrm{~K}$. 
the impact of the voltage (which decreases as temperature increases) on the current of the cell, it would be unnatural to just assume that the temperature is stationary. In this regard, $3 \mathrm{D}$ representations provide a $\mathrm{I}-\mathrm{V}$ and $\mathrm{P}-\mathrm{V}$ characteristics over a continuous range of temperatures. Furthermore, adopted method offers a better view of values. Levels of the output parameters (I or P) are differentiated using graded-tone colours which illustrate better the effect of the sunlight intensity. On Figures 9-11, peak levels correspond to the yellowdominated colour which is light; whereas the lowest levels are found on the dark part (no light) of the plot.

\subsection{Observations}

Maximum values of voltage and power as gathered in Table 2 show that both power and voltage regress significantly when the temperature increases from $280 \mathrm{~K}$ to $460 \mathrm{~K}$. It was also observed that from $32.9 \mathrm{~V}$, the open-circuit voltage could go as low as $12 \mathrm{~V}$ when the PV was operated between $280 \mathrm{~K}$ and $460 \mathrm{~K}$. Figures indicate a drop in maximum power from $247 \mathrm{~W}$ to $143 \mathrm{~W}$ in the same temperature range, which means a decrease of $0.58 \mathrm{~W}$ per Celsius degree. A corresponding power drop rate of $0.56 \%$ was computed thereof, a rate too close to most research findings (Chow, 2010; Natarajan, Mallick, Katz, \& Weingaertner, 2011).

\subsection{Weather and Shading Effects on the Irradiance}

Weather conditions in the surroundings of the PV arrays as well as any form of obstacle cutting out or attenuating the intensity of incident sunlight have a big impact on the irradiance (Ibrahim, 2011). It is also noteworthy to highligt that the sunlight intensity is time-dependent during the day. It is weak in mornings and evenings and maximum at noons. The sunlight, a portion of the electromagnetic radiation released by the sun, is first filtered by the atmosphere before it reaches the earth in the form of sunshine. On its way down through the atmosphere, the sunlight can be interfered with by seasonal or day-based weather conditions or any other obstacles in the form air molecules, aerosols, dust, water drops and ice crystals (Rekioua \& Matagne, 2012). A resulting sunlight is designated as diffuse due to eventual scatterings it undergoes before

Table 2 Maximum power, voltage and temperatures

\begin{tabular}{lllllllllll}
\hline Maximum Voltage (V) & 29.048 & 27.234 & 25.401 & 23.551 & 21.685 & 19.803 & 17.906 & 15.995 & 14.071 & 12.134 \\
Maximum Powers (W) & 190.629 & 178.724 & 166.697 & 154.556 & 142.306 & 129.955 & 117.507 & 104.967 & 92.340 & 79.631 \\
Temperature (K) & 280 & 300 & 320 & 340 & 360 & 380 & 400 & 420 & 440 & 460 \\
\hline
\end{tabular}


it reaches the PVs. On the contrary, in a clear sky, the sunlight is intense and direct during its travel as it relatively encounters no hindrance. The sunlight becomes evident when it appears at horizon in the morning (at sunrise) and its intensity gradually strengthens to hit the peak in noon hours, and progressively regresses to hit the minimum in the evening at sunset, when the sun disappears at horizon in the evening. This can only be observed if there is no weather change on the course of the day like rain and clouds. In terms of energy for PV applications, the amount of power received by a surface per unit area is a standard quantity technically known as the irradiance and its value is determined based on the sunlight intensity at noon. So, given a PV array area, the amount of sunlight power harvested can be determined. Figures 12 and 13 portray the impact of the irradiance on the output power and current of the module.

The variation of the of the maximum currents and powers at irradiance of $200,400,600,800$ and $1000 \mathrm{~kW} / \mathrm{m}^{2}$ are depcited in above graphs and data for current, power and irradiance are gathered in Table 3. Barcharts were also used to disctinctly provide module parameters' peak values for selected irradiance levels (Figures 14 and 15).

Both power and current increase linearly proportionally to the increase of the irradiance. The corresponding change rates are $0.223 \mathrm{~W}$ and $0.008 \mathrm{~A}$

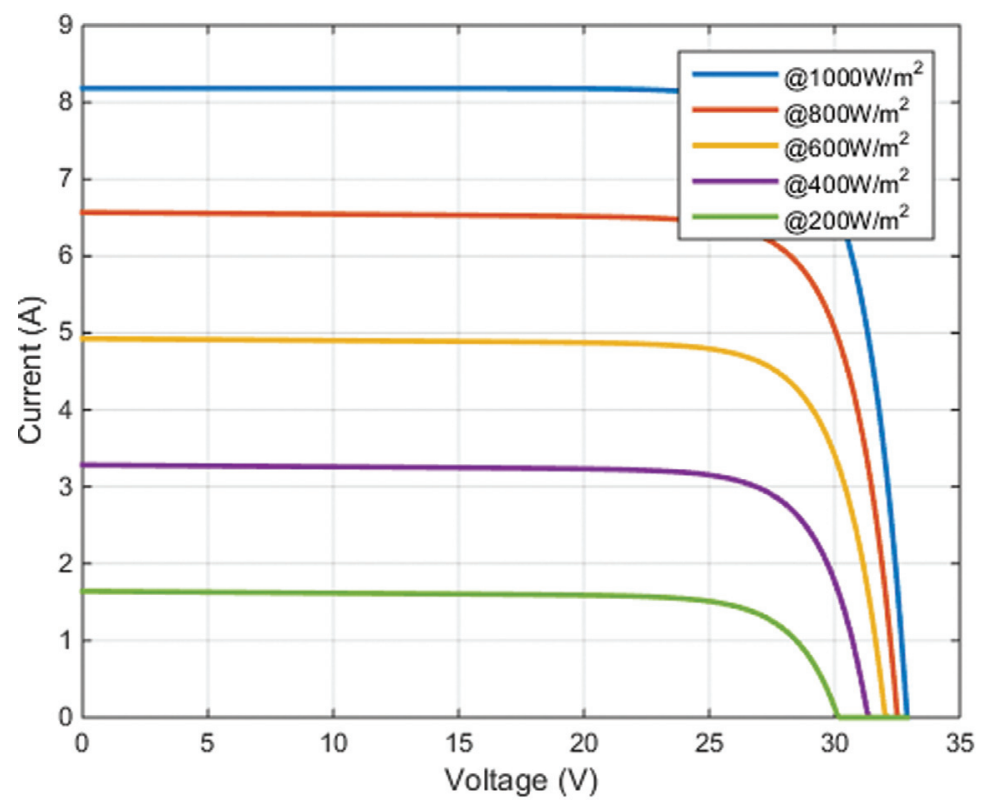

Figure 12 Effect of irradiance variation on the current. 


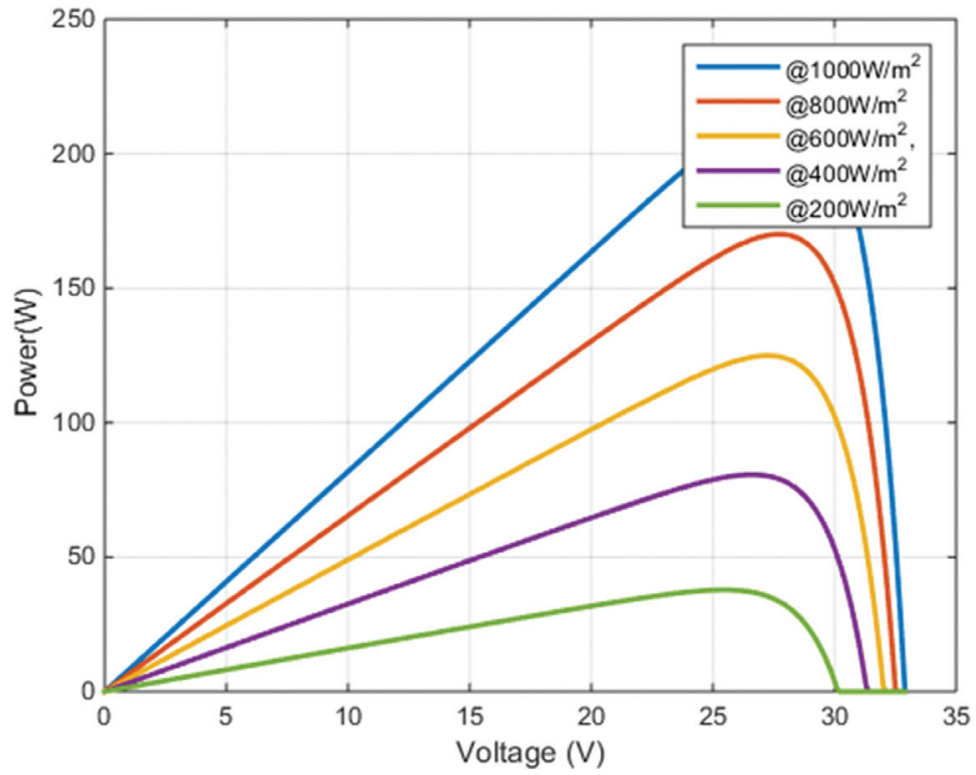

Figure 13 Effects of the irradiance variation on the power.

Table 3 Currents, power and irradiance

\begin{tabular}{lcr}
\hline Irradiance $\left(\mathrm{W} / \mathrm{m}^{2}\right)$ & Current $(\mathrm{A})$ & Power $(\mathrm{W})$ \\
\hline 200 & 1.642 & 37.852 \\
400 & 3.284 & 80.000 \\
600 & 4.926 & 124.935 \\
800 & 6.568 & 171.090 \\
1000 & 8.210 & 215.904 \\
\hline
\end{tabular}

per unit irradiance respectively $\left[\mathrm{kW} / \mathrm{m}^{2}\right]$. These values do also represent the slopes of straight lines joining the peak values of those entities (Power and current) as portrayed in Figures 14 and 15. The rate of change obtained by computing the increase over the minimum values for the current and the power are $0.6 \%$ and $0.5 \%$ per unit irradiance $\left[\mathrm{kW} / \mathrm{m}^{2}\right]$ respectively.

\section{Manufacture Defects and Natural Causes}

For manufacture-related defects, there are those occurring when cells are being strung together, those observable in the process of laying out cells, those happening during the lamination as well as defects directly inherent to the PV base component, the cell. 


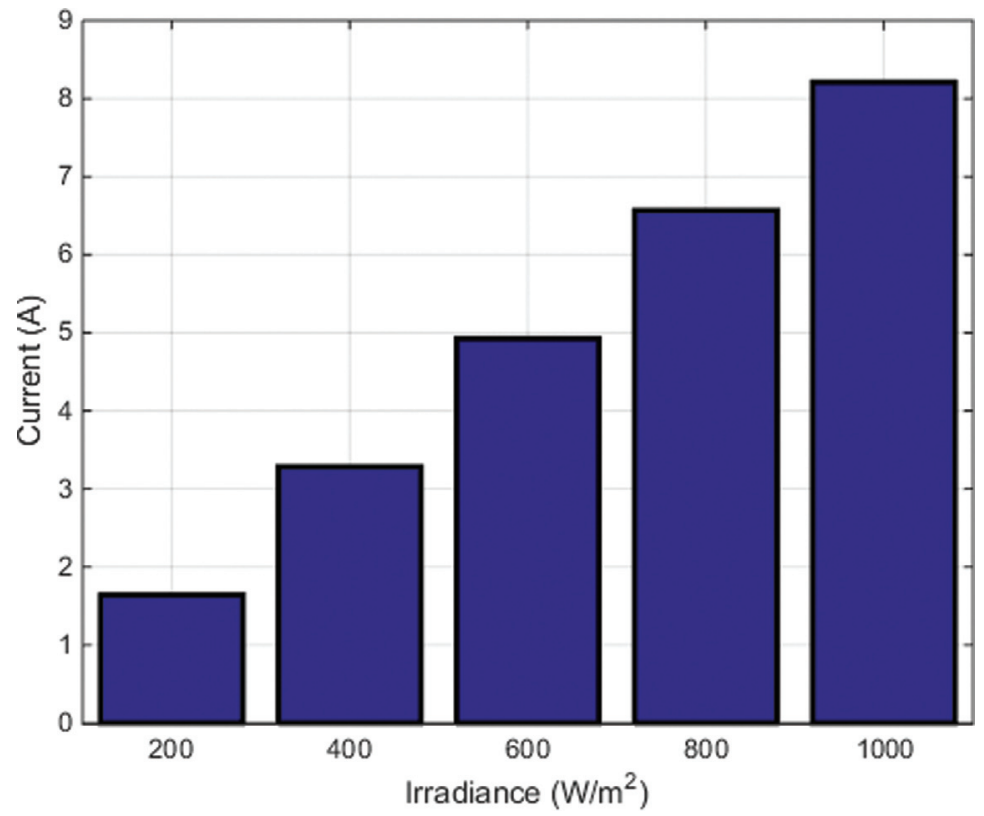

Figure 14 Current vs. irradiance in bar charts.

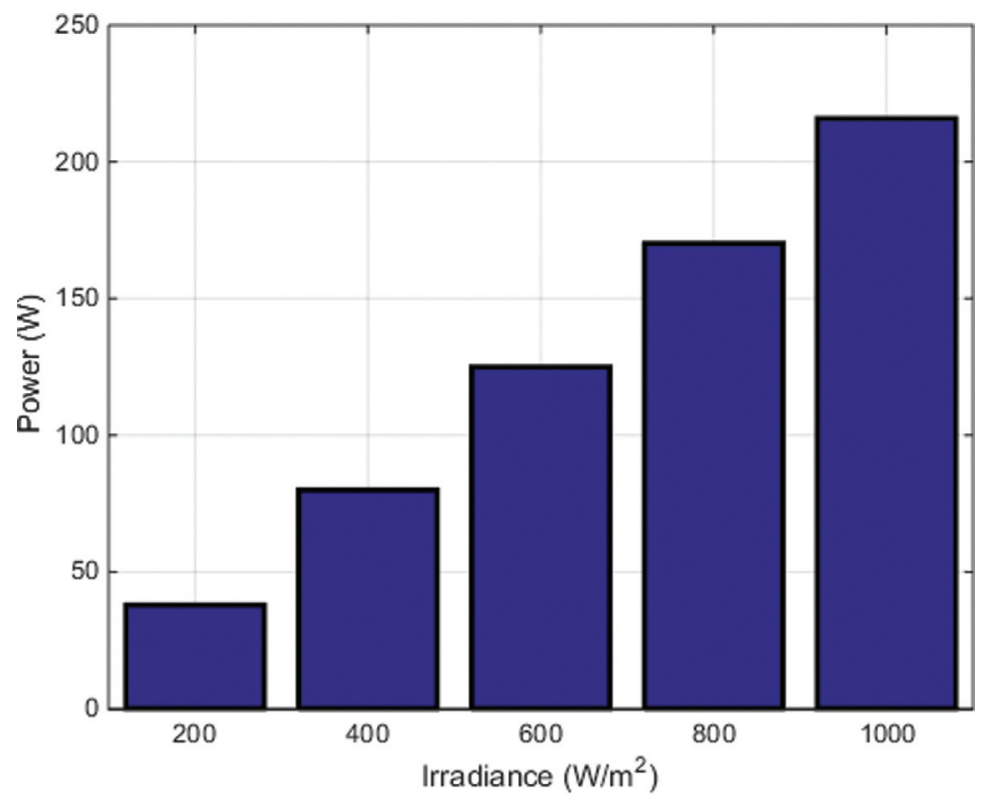

Figure 15 Power vs. irradiance in bar charts. 
Cells are typically strung together by means of soldering. When the soldering is not properly done, cases like poor soldering can give room to high contact resistance between cells, which can also be linked to temperature increase on the solder ribbon. Thus, the cells are connected in series in the layout process using wires. At this stage, possibilities of cells movement can have cell-connecting wires unwantedly joined together occasioning short circuits in the array. The lamination phase consists of encapsulating cells with a membrane in a high temperature process and should take place in vacuumfree and isothermal conditions. Failure to comply with the conditions, lead to bubbles between the membrane and the cells and premature cracks in the formed glass is expected due to the presence of the vacuum and to the thermal uneven distribution in the lamination process. This may also be accompanied with cells disjunction and hence to poor power conversion and arrays' low efficiency. Other defects in PV cells word directly relate to the base component of the array, and commonly characterised by the antireflective coating (ARC) peeling off the Si surface or simply by cells breaking during the fabrication process, shipping or installation.

Solar panels' performance is understood to naturally decline as they age. Studies suggest that cells are subject to a degradation rate of about $0.5 \%$ per year. Furthermore, a cumulative degradation of $20 \%$ module is qualified as a complete failure of a solar module, though the assertion may be a subject of debates (Jordan \& Kurtz, 2013). Even though ageing is natural, some factors are viewed as the catalysers of cells degradation. Thermal conditions have a hand in the progressive deterioration of cells that are meant to operate within nominal operation temperatures. Maintaining PVs in the acceptable operation temperatures preserve their longevity and conversion efficiencies. Though efficiency is primarily believed to depend on the material performing the energy conversion, other factors directly linked to PV cells have been identified. Some are a result of the defects occurring during the manufacturing process (Bhushan, 1999), others are a consequence of the natural ageing (degradation).

\section{Advances in Improvement of PVs Performance}

Sun-tracking and cooling technologies constitute the main strategies that have been intensively researched on to address the effect of external factors on the efficiency of PV cells. In terms of tracking the sun, passive and active technologies are discussed along with their benefits and shortcomings as well as cooling systems specific to the area of PVs of which the aim is to maintain cells' junctions within acceptable range of operation temperatures. 


\subsection{Electronic Controlled Sun-Tracking Systems}

Also referred to as active sun-tracking system, its main essentials consist of two motors (one only for a single-tracking system), a microcontroller, a comparator and a power supply (Juang \& Radharamanan, 2014; Yilmaz et al., 2015). Micro-controlled motors command the navigation of PV arrays latitudinally and longitudinally whereas the comparator is there to ensure that the incident sunlight is received at maximum. A power supply is there to drive the electromechanical system in the process of rotating PV arrays.

The involvement of electronic devices in the operations of sun-tracking systems implies a robust and well-designed structure which is not susceptible to mechanical vibrations eventually caused by winds and other weather fluctuations. Despite their contribution to the efficiency, active sun-tracking systems are criticized for their parasitic aspect as they need to consume power in order to operate.

\subsection{Passive Sun-Tracking Systems}

This type of systems are purely passive and fully mechanical (Clifford \& Eastwood, 2004; Narendrasinh Parmar, Parmar, \& Gautam, 2015). The rotation of the PV arrays is governed by the gravity principle. Such mechanical systems mainly comprise two metallic communicating cylinders placed at either side of the solar panel, a fluid and a damper as well as a pivot which is placed at equal distance from the assembly's ends (Clifford \& Eastwood, 2004). The rotation of the assembly supporting the PV system takes place when the fluid moves from one cylinder to the other. This happens when the sun heats the fluid which in turn evaporates. The subsequent mass imbalance causes the movement of the PV arrays. The damper is used to moderate the speed of the solar panels. However, mechanical systems are delicate to set up especially because the use of the fluid requires a careful attention. In terms of efficiencies, passive systems provide between 23-25\% power increase over fixed tilt solar modules (Clifford \& Eastwood, 2004; Narendrasinh Parmar et al., 2015).

\subsection{Disadvantages of Sun-Tracking Systems}

While sun-tracking systems are well known for power an efficiency increase, they suffer from shortcomings. Lapidot et al., (2014) highlighted some weaknesses of sun-tracking systems and concluded that stand alone PV home kits are still a better, reliable and simple source of energy which requires little in 
terms of development, installation and maintenance. His critics of sun-tracking systems were based on the cost involved in their development, the involvement of moving parts (such as gears, motors), maintenance costs required for eventual broken parts in addition to running on electric power. The reliability of such systems was hence put to question. Juang \& Radharamanan (2014) provided the requirements and limitations he considered while designing his systems. Error at levels of hardware and software design should be eliminated or controlled to ensure system stability and resistance to weather fluctuations. He also mentioned resistance to temperature and to minor mechanical stresses.

Moreover, like any electronic device, electronic-driven-sun-tracking systems are naturally sensitive to temperature increase (Kim, Joshi, \& Fedorov, 2008; Wang \& Chen, 2009), foretells risks of premature system's failure. The reliability of sun-tracking systems is put in doubt as they can only withstand minor mechanical stresses. Thus, their effectiveness should therefore be understood to be good in zones of fair weather and less wind.

\subsection{PV Cooling Technologies}

Since positive temperature gradients act opposing PVs' efficiencies, negative gradients are believed to act in favour of good energy conversion ratios. A literature survey conducted showed that the cooling had a notable impact in terms of performance of PVs. Apart from maintaining PVs within prescribed temperatures, cooling could result in the release of heat energy release by virtue of heat exchange principle which can be further converted in electricity through a thermoelectric process.

A review article authored by Chow (2010) discusses the PV thermal (PVT) hybrid technologies. Solar and thermal conversions are integrated in one unit to produce either electricity or heat. The rationale of his research was the effects of temperature raise on PV performance. He indicated that the efficiency would drop by $0.4 \%$ per ${ }^{\circ} \mathrm{C}$ for concentrated $\mathrm{Si}$ cells and high temperatures could permanently damage the structure of PVs. Findings on PVTs have proven to be useful when heat as well as electricity services are needed. Thus, allowing saving on air-conditioning electricity bills especially in winter time. Temperature between 5 and $7^{\circ} \mathrm{C}$ could be topped to the ambient through an air-type PVT while preserving both the efficiency and lifespan of Si-cells (Long \& Memik, 2010).

Chow (2010) discussed a variety of PVT systems in detail amid flat-platecollector systems, PVT heat pumps and concentrator-type PVT systems. With regards to the flat-plate PVT collectors, two types emerged: Air-type and 
liquid-type collector systems. The efficiencies of the air-type PVT (PVT/a) have been found to be between $38 \%$ and $75 \%$ whereas liquid-types (PVT/w) proved to be significantly more efficient with percentages lying between 55\% and $80 \%$. These results referred to the data collected at the University of Patra in Greece during noon hours (Zondag, 2008). The study also claimed that higher values were attained by involving reflectors in the design of PVTs. On the other hand, Zhu et al. (2011) conducted a study ion cooling PV cells under higher concentration using deionized water. Under one sun, $30^{\circ} \mathrm{C}$ of cooling water and $17^{\circ} \mathrm{C}$ ambient temperature, PV modules could be maintained at a temperature of $45^{\circ} \mathrm{C}$. Similar results could be realized by the latter author (Zhu et al., 2010), by using dimethyl Silicon to cool concentrated PVs (CPVs) through in an immersive process. Heat transfer of $3 \mathrm{~kW} / \mathrm{m}^{2}$ and maximum acceptable temperature of $45^{\circ} \mathrm{C}$ could be accomplished by immersing the module in the liquid circulated in a pipe-pump-valve system.

It is noteworthy to highlight that most research has rather stressed on cooling of CPVs which are usually meant to operate at very high temperatures.

\section{Conclusion and Recommendations}

Further to the efforts in making PVs a sustainable and reliable solar energy conversion platform, there is a need of cautiously considering installation and operation requirements to ensure optimal conversion efficiency and life span. Narendrasinh Parmar et al. (2005) listed the factors affecting solar panels efficiency as follows:

Panel orientation: For a maximum sunlight reception, solar panels should be fitted on the roof side facing the sun's movement. This implies that solar panels should be installed facing the North in the southern hemisphere whereas they should face the South in the Northern hemisphere. Otherwise, solar panels which are not properly oriented will receive the sunlight for a limited number of hours per day. Either some early morning or late afternoon hours will be missed.

Roof and panel pitch: The slope for solar panels and roof should be normal to the sun's apparent movement. Lower or higher pitch can result in solar panels' poor sunlight reception. In this regard, laying solar modules flat on the roof which might have not been designed to meet optimum tilt and pitch angle for solar modules' sunlight reception could result in energy conversion losses.

Temperature: The effect of temperature increase impacts on the efficiency and the lifespan of solar cells. However, in many cases, arrays are tightly laid 
on roof sheets or tiles, an approach that does not favor and natural ventilation. This study therefore suggests that solar modules' installation take into account of any avoidable cause of temperature increase.

Shade: Described as the enemy of the energy, a shade on one solar panel can shut down the energy production of the rest of the panels. It is therefore important to make sure any form of obstacle to the incident sunlight or impurities deposited on solar arrays is minimized as much as possible.

However, despite these recommendations, PVs have been mounted on buildings roofs without strictly minding the level of exposure to the sun and of the resulting PV output. This in fact a consequence of having buildings conventionally laid out according to roads' plans and to the variety of roof shapes while optimum solar exposure to the sun is not necessarily a driving factor for road planning and roof pitching.

Therefore, in line with poor-efficiency concerns, the authors therefore reminds that PVs be mounted on roofs considering the regional PVs' optimum angle especially for fixed-tilt solar panels. They also suggest that PVs be mounted a bit above the roof, which would allow heat transfer to the atmosphere to happen in a natural ventilation process; thus keeping PVs close to their nominal operational temperatures.

\section{References}

[1] Ã, H. Z., Wei, J., Wang, K., Wu, D., Al-Hasan, A. Y., Altermatt, P. P., and Wantz, G. (2011). The history of solar. Sol. Energy Mater. Sol. Cells 93, 1461-1470.

[2] Bagnall, D. M., and Boreland, M. (2008). Photovoltaic technologies. Energy Policy, 36, 4390-4396.

[3] Bhushan, S. (1999). "Impurities and defects in photovoltaic Si devices: a review,"in Proceedings of the Tenth International Workshop NREL (pp. 1-59). Delhi.

[4] Chow, T. T. (2010). A review on photovoltaic/thermal hybrid solar technology. Applied Energy, 87, 365-379.

[5] Clifford, M. J., and Eastwood, D. (2004). Design of a novel passive solar tracker. Solar Energy, 77, 269-280.

[6] Green, M. A. (2011). "Third Generation Photovoltaics: First Generation Wafers/Ribbons,'In Photovoltaics-Electricity from Sunlight, 1-18.

[7] Ibrahim, A. (2011). Analysis of Electrical Characteristics of Photovoltaic Single Crystal Silicon Solar 
[8] Cells at Outdoor Measurements. Smart Grid and Renewable Energy, 2, 169-175.

[9] Jordan, D. C., and Kurtz, S. R. (2013). Photovoltaic degradation rates An Analytical Review. Progress in Photovoltaics: Research and Applications, 21, 12-29.

[10] Juang, J., and Radharamanan, R. (2014). "Design of a Solar Tracking System for Renewable Energy," in Proceedings of 2014 Zone 1 Conference of the American Society for Engineering Education.

[11] Kibria, M. T., Ahammed, A., Sony, S. M., and Hossain, F. (2014). A Review?: Comparative studies on different generation solar cells technology. In International Conference on Environmental Aspects of Bangladesh (pp. 51-53). Dhaka.

[12] Kim, Y. J., Joshi, Y. K., and Fedorov, A. G. (2008). An absorption based miniature heat pump system for electronics cooling. Int. J. Refrigeration, 31, 23-33.

[13] Lapidot, D., Dror, R., Vered, E., Mishli, O., Levy, D., and Helman, Y. (2014). Automatic Solar Tracking System. Plant Pathology, 1, 192-195.

[14] Long, J., and Memik, S. O. (2010). A Framework for Optimizing Thermoelectric Active. In DAC10- June 13-18 (pp. 591-596). Anaheim.

[15] Moharram, K. A., Abd-Elhady, M. S., Kandil, H. A., and El-Sherif, H. (2013). Enhancing the performance of photovoltaic panels by water cooling. Ain Shams Engineering Journal, 4, 869-877.

[16] Narendrasinh Parmar, A. J., Parmar, A. N., and Gautam, V. S. (2015). Passive Solar Tracking System. Int. J. Emerging Technol. Adv. Eng., ISO Certified Journal, 5, 67-88. Available at: Www.ijetae.com

[17] Natarajan, S. K., Mallick, T. K., Katz, M., and Weingaertner, S. (2011). Numerical investigations of solar cell temperature for photovoltaic concentrator system with and without passive cooling arrangements. Int. J. Therm. Sci. 50, 2514-2521.

[18] Pachpande, S. G., and Jalgaon. (2012). Studying the Effect of Shading on Solar Panel using MATLAB. Int. J. Sci. Appl. Inf. Technol. 1, 46-51.

[19] Parida, B., Iniyan, S., and Goic, R. (2011). A review of solar photovoltaic technologies. Renewable and Sustainable Energ. Rev. 15, 1625-1636.

[20] Rekioua, D., and Matagne, E. (2012). Optimization of photovoltaic power systems: Modelization, Simulation and Control. Green Energy and Technology, Vol. 102. Springer Science \& Business Media, Berlin.

[21] Sabri, L., Benzirar, M., and Student, P. G. (2007). Effect of Ambient Conditions on Thermal Properties of Photovoltaic Cells: Crystalline and Amorphous Silicon. International Journal of Innovative Research in 
Science, Engineering and Technology (An ISO Certified Organization), 3297, 17815-17821.

[22] Segal, A., Epstein, M., and Yogev, A. (2004). Hybrid concentrated photovoltaic and thermal power conversion at different spectral bands. Solar Energy, 76, 591-601.

[23] Wang, Y., and Chen, X. (2009). Advanced Electronic Cooling Technologies, 149-152.

[24] Yilmaz, S., Riza Ozcalik, H., Dogmus, O., Dincer, F., Akgol, O., and Karaaslan, M. (2015). Design of two axes sun tracking controller with analytically solar radiation calculations. Renewable and Sustainable Energ. Rev. 43, 997-1005.

[25] You, L. J., Hao, L. J., and Adele, L. S. (n.d.). Sun and Architecture. GEK 1506 Heavenly Mathematics.

[26] Zhu, L., Boehm, R. F., Wang, Y., Halford, C., and Sun, Y. (2011). Water immersion cooling of PV cells in a high concentration system. Sol. Energy Mater. Sol. Cells 95, 538-545.

[27] Zhu, L., Wang, Y., Fang, Z., Sun, Y., and Huang, Q. (2010). Solar Energy Materials \& Solar Cells: An effective heat dissipation method for densely packed solar cells under high concentrations. Sol. Energy Mater. Sol. Cells 94, 133-140.

[28] Zondag, H. A. (2008). Flat-plate PV-Thermal collectors and systems: A review. Renewable and Sustainable Energ. Rev. 12, 891-959.

\section{Biographies}

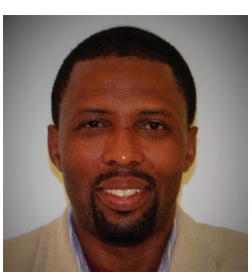

Janvier Kamanzi holds BTECH, MTECH and D. Eng. degrees in Electrical, Electronic and Computer Engineering respectively obtained in 2012, 2014 and 2017 at the Cape Peninsula University of Technology (CPUT), Cape Town, South Africa. His research has focused on improving the conversion efficiencies of Photovoltaics and yielded a novel sun-tracking technology as well as a good number of publications. 
In the pursuit of his postgraduate studies, Dr. Kamanzi has been working as a lecturer at the same University. He has also been serving as a reviewer for quality peer-reviewed journals and conferences.

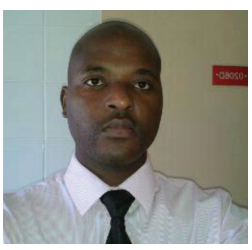

Matthew Sibanda attended at the National University of Science and Technology in Zimbabwe where he completed a B. Eng. Honors in Electronic Engineering. He then completed an M.Sc. in Electronics with the Ecole Superieure d'Ingenieurs en Electrotechnique an Electronique (ESIEE) and an MTECH with the Cape Peninsula University of Technology.

$\mathrm{He}$ is currently working as lecturer at Mangosuthu University of Technology (MUT). 
